\title{
REFLEXÕES SOBRE O CETICISMO \\ A PARTir do Cogito Agostiniano
}

\author{
REFLECTIONS ON CETICISM \\ FROM THE AGOSTINIAN COGITO
}

\section{Carlos Eduardo de Carvalho Vargas * Clodoaldo da Luz **}

\begin{abstract}
RESUMO
Desde a antiguidade, até a filosofia contemporânea, os filósofos têm enfrenta do questões relacionados ao conhecimento e ao ceticismo. Como obter a certeza diante de tantas dúvidas epistemológicas? Santo Agostinho enfrentou as questões céticas, tomando o caminho do autoconhecimento a partir de uma reflexão epistemológica sobre o cogito. Este artigo visa analisar a posição de Santo Agostinho diante do ceticismo. Ele enfrentou os céticos e, para isso, reconheceu a importância do autoconhecimento. A filosofia cristã de Santo Agostinho pode mostrar possibilidades para repensar o papel filosófico do autoconhecimento e a importância da superação do ceticismo.
\end{abstract}

Palavras-chave: Ceticismo. Agostinho. Autoconhecimento.

\section{ABSCTRACT}

From ancient times to contemporary philosophy, philosophers have faced questions of knowledge and skepticism. How to get certainty in the face of so many epistemological doubts? St. Augustine faced the skeptical questions, taking the path of self-knowledge from an epistemological reflexion on the cogito. This paper aims to analyze the position of Saint Augustine in the face of skepticism. He confronted the skeptics and he recognized the importance of self-knowledge. The Christian philosophy of St. Augustine may show possibilities for rethinking the philosophical role of self-knowledge and the importance of overcoming skepticism.

Keywords: Skepticism. Augustine. Self-knowledge.

\section{INTRODUÇÃO}

Em seu percurso histórico, o discurso racional filosófico se deparou com indagações epistemológicas que remetem a um posicionamento cético sobre a possibilidade do ser humano obter o conhecimento sobre algo. Mediante essa dificuldade, alguns filósofos, desde Pirro de Élis, optaram pela suspensão do

\footnotetext{
* Doutor em Filosofia pela Pontifícia Universidade Católica do Paraná. É analista do IBGE e membro da Nordic Society of Phenomenology e do Edith Stein Circle (International Association for the Study of the Philosophy of Edith Stein). E-mail: carlos.vargas@ibge.gov.br

** Especialista em Filosofia pelo Centro Univ ersitário Claretiano de Batatais. Ésacerdote da Diocese de Jacarezinho e Mestrando em Filosofia pela Universidade Federal do Paraná. E-mail: clodoaldoluz@outlook.com
} 
assentimento à validade dos juízos. Tal posicionamento cético em relação à questão do conhecimento questiona de que forma se poderia arregimentar a discussão filosófica, se essa tem a pressuposição de levar o homem, por meio da reflexão racional, à pretensa contemplação do conhecimento? Assim, não seria uma incongruência perseguir o que não se pode almejar: o conhecimento? E a suspensão plena do assentimento à validade dos juízos não teria consequências ética, na medida em que inviabilizaria a ação humana, na impossibilidade de tomar decisões racionais?

O ceticismo marcou a história da filosofia: da antiguidade até o período contemporâneo. Algumas formas dos ceticismos foram especialmente significativas na Antiguidade e no Renascimento. Este artigo não apresentará uma história do ceticismo universal, mas fará uma análise da reflexão agostiniana sobre o ceticismo. Objetivando responder emergencialmente a essas inquietações céticas, Agostinho teceu elucubrações filosóficas com o fito de apontar uma diretriz, a partir da qual o conhecimento é possível ao homem. Cada qual, com sua ênfase metodológica, refletiu sobre a importância do autoconhecimento como ponto de partida do conhecimento filosófico. O que se pretende mostrar são as convergências e divergências de filósofos que buscaram superar o ceticismo no contexto medieval, depois da antiguidade, e no período contemporâneo, depois da modernidade.

\section{DO COGITO AO AUTOCONHECIMENTO: A REFUTAÇÃO AgOSTINIANA DA POSTURA CÉTICA ACADÊMICA.}

A desilusão de Agostinho, com a solução racional disponibilizada pela seita maniqueísta, levou-o ao ceticismo. Desiludido ao tentar encontrar a verdade por intermédio da autoridade e da razão ${ }^{1}$, o Hiponense ${ }^{2}$ passou a considerar que a postura cética acadêmica fosse a mais adequada em relação à possibilidade do conhecimento (AUGUSTINE, 1912, p. 245). Consequentemente, seu afã de contemplar a verdade se arrefeceu. Agostinho conhecera tal postura filosófica através da leitura da obra de Cícero:

\footnotetext{
1 A autoridade e a razão são consideradas por Agostinho como as duas vias de acesso ao conhecimento (AUGUSTÍN, 2008, p. 224-225).

2 Esta nomenclatura será usada para designar Agostinho, pois ele ocupou a cátedra de Hipona, que era o nome da cidade que, atualmente, é chamada de Annaba, na Argélia.
} 
Com Zenão [....] Arcesilau estabeleceu toda sua disputa, não por pertinácia ou intenção de vencer como ao menos me parece, mas pela obscuridade desses assuntos [...] Arcesilau negava haver algo que se pudesse saber, nem sequer aquilo mesmo que Sócrates se teria mantido - que soubesse que nada sabia; pensava assim estarem profundamente ocultas as coisas todas e não haver algo que se pudesse discernir ou entender, por essas causas, na da covinha professar, nem afirmar seja o que for, nem aprovar com o assentimento ${ }^{3}$ (CÍCERO, 2012, p. 135).

Três fatos fizeram Agostinho superar essa crise e reconsiderar a admiração que tinha, outrora, pela postura cética acadêmica: "a participação nos sermões de Ambrósio, descoberta dos livros neoplatônicos e um renovado estudo da escritura4" (DUTTON, 2016, p. 14). A partir da leitura dos neoplatônicos, o Hiponense reconsiderou a postura acadêmica cética apresentada por Cícero, seu mestre na Filosofia. Sentiu-se impelido a contrapor tal posicionamento, que negava a impossibilidade do conhecimento e do assentimento ao homem.

A primeira tarefa de Agostinho, ao refugiar-se em Cassicíaco, na casa de campo de seu amigo Verecundo, foi contrapor-se ao ceticismo dos acadêmicos. Por isso, Agostinho, com seus amigos, elaborou o seu primeiro diálogo filosófico: Contra os Acadêmicos. Segundo Gilson (2006, p. 86) e Blake Dutton (2016, p. 231), o Hiponense fundou o seu cogito nesta obra Contra os Acadêmicos (AUGUSTÍN, 1963, p. 147-148):

Mas como não seria ele abalado, se, de uma parte, njão se pode encontrar nada que seja tal [isto é, conforme o que exige Zenão] e, de outra, só se pode conhecer com certeza o que é tal? Se assim fosse, seria melhor dizer que o homem não pode alcançar a sabedoria que dizer que o sábio não sabe por que vive, como vive, nem se vive, enfim, o que ultrapassa tudo o que se pode dizer de absurdo, de extravagante e de insensato, que se pode ao mesmo tempo ser sábio e ignorar a sabedoria (AGOSTINHO, 2008, p. 118)

\footnotetext{
3 No original: "Cum Zenone... Arcesilas sibi omne certâmen instituit, non pertinácia aut studio uincendiut quidem mihi uidetur, sed earum rerum obscuritate [...] Itaque Itaque Arcesilas negabat esse quicquam quod sciriposset, ne illud quidem ipsum quod Socrates sisi reliquisset, ut nihil scire se sciret; sic omnia latere censebat in oculto neque esse quicquam quod cerni aut intellegi posset; quibus de causis nihil oportere neque profiteri neque affimare quemquam neque assenssione approbare" (tradução livre).

4 No original: "Attendance at Ambrose's sermons, Discovery of the books of the Platonists, and renewed study of scripture" (tradução livre).
} 
No trecho acima, Agostinho questionou os acadêmicos ao pressuporem que o sábio é aquele que suspende o assentimento perante a "certeza" da impossibilidade do homem em contemplar o conhecimento. Pois, o sábio precisa saber por que vive. No caso em questão, o sábio acadêmico vive porque busca diligentemente a verdade. Ora se essa é a finalidade do sábio, ele sabe como vive. No caso, o sábio acadêmico nunca concede temerariamente o assentimento. Enfim, quem sabe porque vive e como vive, obrigatoriamente sabe que vive. Deste modo, o sábio ao menos tem ciência que vive, do porquê vive e como vive. No mesmo diálogo, Agostinho explanou a necessidade de conhecer a realidade inteligível, a fim de que a alma possa se autoconhecer (AGOSTINHO, 20087, p. 140).

Aqui nesse trecho já, de forma não muito aparente, já se incute o tríplice conhecimento: pois como não pode o sábio ter ciência de por que vive, ou seja se existe; como se vive, ou seja se vive; como não entender se se vive, ou seja não ter plena consciência de que entende que esta vivo.

Suscitando tal possibilidade da alma conhecer a si gradativamente através do autoconhecimento mediado pela autorreflexão, o Hiponense visou estabelecer um conjunto de verdades em primeira pessoa, que responderiam o desafio da postura cética acadêmica. Com esse intuito, Agostinho apresentou a possibilidade da verdade das coisas tais e quais se apresentam à pessoa (AGOSTINHO, 2008, p. 126-127).

Tal resposta de Agostinho ao desafio cético reafirmou o seu cogito como uma resposta contundente ao desafio da postura acadêmica. O Hiponense, ao afirmar que tal objeto lhe parecia branco ou frio, não estava advogando que tais coisas assim são. Ele estava supondo que algo lhe parece, ou seja, estava se conscientizando de que pode perceber algo. Deste modo, Agostinho (2008) pressupôs uma nova forma de concepção da verdade: a verdade em primeira pessoa.

Tal classe de verdade parece ser consistente ao propósito de Agostinho. Pois o que se assevera é o fato de perceber algo. Semelhante afirmação é apreensível, pois a pessoa, ao parecer que percebeu algo, concebe o fato de parecer como verdade, assumindo que algo lhe aparece de determinada forma. A isto deve-se necessariamente conceder o assentimento, pois é patente que a pessoa assente que está percebendo algo, sendo passível de veracidade.

Esse conhecimento apresentado pelo Hiponense não é obtido por intermédio dos sentidos, os quais são os alvos da postura cética acadêmica, e sim da 
introspecção, da pura intelecção. Perante isso é que Dutton (Cf. Op. Cit. 2016, p. 239) indica que, partindo desse conhecimento, é possível verificar um outro tipo de conhecimento: o conhecimento em primeira pessoa.

A possibilidade do conhecimento dessa verdade não provém dos sentidos, mas da introspecção. Esse é um contundente argumento de Agostinho contra a postura cética, pelo fato da postura acadêmica centrar sua negativa da impossibilidade do conhecimento. Conforme Gilson (2006, p. 93), a postura cética provém do questionamento do conhecimento sensível. Por outro lado, o Hiponense adota, como critério de verdade, a introspecção.

É uma classe de verdades que são apreendidas por um meio de cognicão que é distinto da sensação e que não é impugnado pelas considerações que impugnam a sensação como um meio de apreensão. Isto é introspecção, o que ocorre quando a mente volta sua atencão sobre si em um exame de sua própria existência, poder, atividades, e conteúdos, os quais são imediatamente presentes a ela 5 (DUTTON, 2016, p. 211-212).

Levando em consideração, que a postura cética acadêmica provém do questionamento do conhecimento sensível como critério de verdade, a evidência do pensamento puro é a resposta mais contundente ao desafio cético, por escancarar a possibilidade do conhecimento e da concessão do assentimento (GILSON, 2006, p. 93). Outrossim, Gareth Matthews concorda a esse respeito com Gilson, pois o cogito é a "mais interessante resposta de Agostinho ao desafio do ceticismo acadêmico" (MATTHEWS, 2007, p. 39).

Isto porque contra a postura cética acadêmica da incogniscibilidade da Verdade e da suspensão do assentimento, a evidência da própria existência é a melhor resposta. Mesmo que se ponha em duvida essa proposição só é possível fazêlo mediante a própria existência colocada em xeque. Ora, quem duvida é quem existe, senão não teria como fazê-lo. Necessariamente se deve assentir a isto: à própria existência.

\footnotetext{
5 No original: "Is a class of truths that are apprehended by means of a mode of cognition that is distinct from sensation and that is not impugned by the considerations that impugn sensation as a means of apprehension. This is introspection, with occurs when the mind turns its attention back on itself in examination of its own existence, powers, activities, and contents, all of which are immediately present to it" (tradução livre).
} 
Gradualmente, ainda com o intento de responder ao desafio cético da postura acadêmica, Agostinho nos Solilóquios (Soliloquia), dialogando consigo mesmo, reestruturou e corroborou o cogito, delineando que o autoconhecimento possível a partir das reflexões inscritas no cogito, como ponto de partida consistente para o conhecimento (AUGUSTÍN, 1969, p. 473-474):

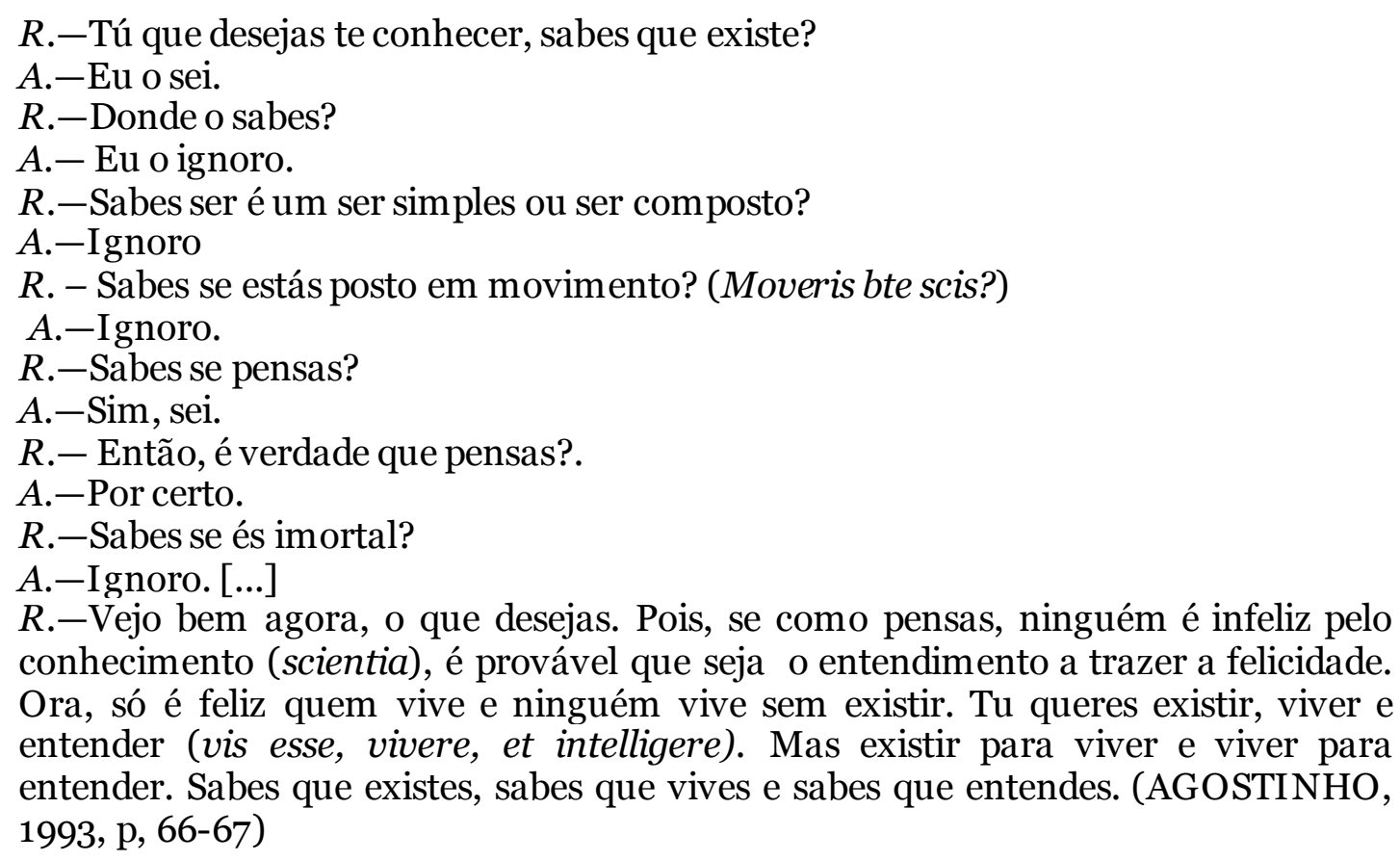

A mediação na qual Agostinho percorreu o seu itinerário em busca da verdade inscreve a existência do sujeito pensante, concedendo-lhe a primazia entre as certezas, conforme afirmou Étienne Gilson: “a certeza da existência do sujeito pensante é... imediatamente fundada sobre a certeza da existência do pensamento, por oposição a qualquer outra certeza ulterior, e essa verdade incontestável é também a primeira de todas as certezas" (GILSON, 2006, p. 90).

Brian Stock (2010, p. 96), na sua obra Diálogo interior de Agostinho: o solilóquio filosófico na Antiguidade tardia (Augustine's Inner Dialogue: The Philosophical Soliloquy in Late Antiquity), analisou que o cogito agostiniano visa referendar o autoconhecimento por meio da pressuposição de Agostinho de estabelecer a própria existência mediante o fato de estar cônscio de sua atividade mental. 
Assim para Stock quando Agostinho:

Em Solilóquio 2.I.I, Agostinho expressa o desejo de conhecer a si mesmo. Como primeiro passo na investigação, a Razão pergunta a ele se ele sabe que existe. Inicialmente, ele responde afirmativamente, mas, quando convidado a explicar como esse conhecimento surgiu, ele não pode fazê-lo. A razão então passa a questioná-lo de maneira socrática a respeito de seu conhecimento de seu corpo e mente. Ele responde negativamente a perguntas sobre a certeza de seu conhecimento sobre a composição e o movimento de seu corpo. Ela então pergunta se ele sabe que é o processo de picar, refletir ou meditar; em outras palavras, se ele está consciente da atividade de sua mente: "Cogitaris te scis?" Ele responde que sabe disso: "Scio". Sobre isso ele não tem dúvidas. A existência de seu ego ou alma é assim estabelecida. ${ }^{6}$ (STOCK, 2010, p. 95)

No diálogo citado acima (AUGUSTÍN, 1969, p. 474), o termo cogitaris indica a evidência do pensamento e a afirmação da certeza de ser um sujeito pensante. Ele o faz partindo de um pressuposto ontológico, da existência, perpassando pela inferência de que se vive, para daí, atinar um viés lógico, a de que se entende. Nessa esteira, o autoconhecimento ensejado por Agostinho se dá através da existência de si. O qual é cônscio de sua atividade mental e que por meio dela é capaz de elencar certezas que lhe são evidentes através de uma argumentação racional. A partir dessa certeza, é possível, segundo Étienne Gilson (2006), responder satisfatoriamente ao desafio cético da postura acadêmica:

Uma ligação profunda entrelaça as teses mestras da metafísica agostiniana, a tal ponto que elas parecem se fundir umas nas outras à medida que nos aprofundamos nelas. Ao apreender-se a si mesmo, o pensamento nos liberta do ceticismo; mas pensar é viver; viver é agir como uma substância que anima e, consequentemente, também distinguir-se do corpo que a alma vivifica; distinguir-se do corpo é, enfim, apreender-se como uma substância irredutível à extensão (GILSON, 2006, p. 117).

\footnotetext{
6 No original: "At Soliloquia 2.I.I, Augustine express a desire to know himself. As a first step in the inquiry, Reason asks him wheter he knows that exist. He inittially replies in the affirmative, but when invited to explain how this knowledge has come about he cannot do so. Reason then proceeds to question him in Socratic manner concerning his knowledge of his body and mind. He replies negativ ely to queries about the certainty of his knowledge on such matter as his body's composition and movement. She then asks wheter he knows that he is the process of thiking, reflecting, or meditating; in other words, wheter he is conscious of his mind's activity: 'Cogitaris te scis?' He answers that he knows this: 'Scio.'About this he has no doubt. The existence of his self or soul is thus established” (tradução livre).
} 
Através desse exercício intelectual da sua Razão, Agostinho foi ao encontro dos seus objetivos epistemológicos: conhecer a si e a Deus. Conforme referendado nos Solilóquios (AUGUSTÍN, 1969, p. 441-442). Para o Hiponense, o conhecimento de Deus e da alma são os dois problemas que constituem o objetivo discursivo filosófico (AUGUSTÍN, 1969, p. 683). Na obra O livre-arbítrio (De libero arbítrio), O Hiponense, segundo Étienne Gilson, (2006, p. 90), partiu da existência de seu interlocutor Evódio para inferir a prova da existência de Deus (AUGUSTÍN, 1963 p. 254-255).

Eis o trecho em questão:

Ag.-Se quiseres, investiguemos na seguinte ordem:

$1^{o}$ - procuremos como provar a existência de Deus;

$2^{O}$ - se na verdade tudo o que é bem, enquanto bem, vem de Deus;

$3^{O}$ - enfim, se será preciso contar, entre os bens, a vontade livre do homem.

Uma vez essas questões esclarecidas, aparecerá suficientemente, eu o penso, se essa vontade foi dada aos homens com justeza.

Assim pois, para partirmos de uma verdade evidente, eu te perguntaria, primeiram ente, se existe. Ou, talvez, temas ser vítima de engano ao responder a essa questão? Todavia, não te poderias enganar de modo algum, se não existisses.

Ev. É melhor passares logo adiante, às demais questões.

Ag. Então, visto ser claro que existes - e disso não poderias ter certezas tão manifesta, caso não vivesses -, é também coisa clara que vives. Compreendes bem, que há aí duas realidades muito verdadeiras?

Ev. Compreendo-o perfeitamente.

Ag. Logo, é também manifesta a terceira verdade, a saber, que tu entendes?

Ev. É claro. (AGOSTINHO, 1995, p. 80-81)

Assim ele percebe que mesmo quando poderia estar enganado ele sabe que existe, porque senão existisse não teria a menor possibilidade de se enganar. Assim, o Hiponense elenca uma série de possíveis verdades em primeira pessoa que, a seu ver, estariam isentas da dúvida cética.

Deste modo, Hiponense indo na contramão do desafio cético assumido pela Academia, percorrendo uma trilha intelectiva, reafirma a existência de si atingindo a certeza de que pensa, ou seja, parte de uma certeza ontológica à uma lógica para debelar a dúvida acadêmica no seu próprio campo de embate.

Sobre o excerto agostiniano acima, Gareth Matthews divergiu de Étienne Gilson. Matthews considerou que a referida passagem de O livre-arbítrio não tem a pretensão de referendar a possibilidade da existência de Deus. Eis a posição de Matthews sobre referido trecho agostiniano: 
O leitor poderia ser induzido por essa postura a esperar que Agostinho tentasse desenvolver uma prova da existência de Deus baseado na certeza fundamental de nossa própria existência. Mas não é isso o que ele faz. Pelo contrário, Agostinho leva Evódio a concordar sobre um ponto: que não estava muito claro para ele que ele existia, a menos que estivesse vivo e entendesse (MATTHEWS, 2005, p. 139).

Todavia, considerando o que Agostinho dissera nas suas obras $A$ ordem e Solilóquios, que o seu objetivo filosófico era o conhecimento da alma e de Deus, a contribuição de Étienne Gilson correspondeu e ratificou esse intento filosófico de Agostinho. Para o Hiponense, o autoconhecimento é uma etapa fundamental na refutação da postura cética, porque "ao mesmo tempo em que se liberta da dúvida pela certeza de sua própria existência, o pensamento apreende-se como uma atividade vital de ordem superior, pois pensar é viver" (GILSON, 2006, p. 95).

Semelhante certeza necessariamente provém de um autoconhecimento mediado pela reflexão. Portanto, Agostinho enfocou a imperiosidade da interiorização. Tal prerrogativa do Hiponense fora outrora elencada nos Solilóquios (AUGUSTÍN, 1969, p. 517). O enfoque agostiniano da busca da verdade norteada pela interiorização foi de suma importância para o desenvolvimento filosófico posterior: "a influência de santo Agostinho no Ocidente em todo o período medieval explica em grande parte o desinteresse pelo ceticismo" (MARCONDES, 2001, p. 98).

\section{CONSIDERAÇões FINAIS}

$\mathrm{O}$ argumento do cogito arregimentado por Agostinho se mostrou contundente ao desafio da postura cética acadêmica. Sua metodologia relacionou-se com o autoconhecimento do sujeito permeado pela reflexão do Eu existo, Eu vivo e Eu penso trilhada no itinerário filosófico agostiniano. Para o Hiponense, o cogito se tornou um referencial epistemológico, fundando o autoconhecimento na reflexão sobre o ato intelectual.

O princípio do cogito agostiniano está intimamente ligado ao projeto do Hiponense de responder ao desafio cético da postura acadêmica. É em meio a essa tarefa empreendida por Agostinho que surgiu o seu cogito. Tal marco filosófico se contrapôs ao desafio cético da postura acadêmica, a qual centrava seu questionamento nos sentidos como fonte do conhecimento. Ao acentuar a dúvida 
cética, Agostinho chegou a um fundamento epistemológico que não poderia ser negado, o cogito, afastando-se da dúvida universal.

Agostinho, ao responder à postura cética acadêmica, assumiu o cogito como a evidência racional da existência do sujeito. $\mathrm{O}$ Hiponense pressupôs o autoconhecimento como referencial para sua pesquisa sobre a alma e sobre Deus, os quais são objetos da sua filosofia. $O$ autoconhecimento foi um tema presente na história da filosofia desde os diálogos platônicos (Alcebíades I) até a filosofia contemporânea, passando por Cícero, Fílon de Alexandria, Plotino e São Bernardo de Claraval (PLATO, 1997; TONIOLO, 2015).

O ceticismo, em suas diferentes versões, também se manifestou em diversos momentos da história da filosofia. Agostinho teve oportunidade de se confrontar com o pensamento cético no seu contexto, partindo das Sagradas Escrituras e da Teologia para dialogar com a filosofia grega e helenística. Contudo, os contextos históricos diferentes também acarretaram diferenças no sentido do ceticismo e nos instrumentais intelectuais utilizados pelos filósofos estudados.

Luigi Alici $(2006,2012)$ analisou os caminhos da influência agostiniana entre os diferentes critérios epistemológicos dos pensadores da fenomenologia e da hermenêutica contemporânea. O mesmo autor destacou, por exemplo, a influência de Agostinho em Martin Heidegger (1997) e Karl Jaspers, além de Edmund Husserl (1973). Pascal Marin (2008, p. 63-64) expressou, com relativa surpresa, a influência agostiniana sobre a filosofia contemporânea, apesar da distância cultural de alguns pensadores em relação à teologia ocidental. Mesmo sem partilhar seus pressupostos teológicos ou a "doutrina cristã", alguns filósofos contemporâneos se aproximaram de Agostinho em virtude da universalidade dos seus questionamentos que se tornaram referências clássicas para o pensamento ocidental.

O professor Juvenal Savian Filho (2015) também refletiu sobre a relação histórica da psicologia agostiniana com a filosofia contemporânea. Ele recordou que Franz Brentano (1936), por exemplo, fez menções explícitas às teologias de Agostinho e Tomás de Aquino apenas como analogia, sem querer repetir os modelos teológicos anteriores. Apesar dessas divergências, "não faz sentido recusar-se a ver que há continuidades na história do pensamento, mesmo em meio a mudanças (e porque há mudanças)" (SAVIAN FILHO, 2015, p. 189). 
Conceitos agostinianos como cogito, intentio e inventio não deixam de ter um sentido no solo da reflexão contemporânea. Agostinho, seguindo as temáticas relacionadas com a sua conversão ao cristianismo, também buscou aquilo que é essencial, passando por muitos e difíceis trabalhos. A partir da reflexão agostiniana sobre o ceticismo, por meio da filosofia do cogito agostiniano, espera-se abrir possibilidades para uma filosofia de inspiração cristã a partir de uma problemática epistemológica.

\section{REFERÊNCIAS}

AGOSTINHO, Santo. Solilóquios. Trad.: Nair de Assis Oliveira, 1993, p. 153

AGOSTINHO, Santo. O livre-arbítrio. Trad.: Nair de A. Oliveira. São Paulo: Paulus, 1995. 300p.

AgOSTINHO, Santo. Contra acadêmicos; A ordem; A grandeza da alma; 0 mestre. Trad.: Agostinho Belmonte. São Paulo: Paulus, 2008.

AgOSTINO, Sant'. La Vera Religione. Trad.: Antonio Pieretti. Roma: Città Nuova, 1992. $190 \mathrm{p}$.

\section{ALICI, Luigi. Augustin notre contemporain. Revue d'éthique et de théologie} morale, Paris, 2006 / 3 ( $\mathrm{n}^{\circ}$ 240), p. 47-59. Disponível em: <http://www.cairn.info/revue-d-ethique-et-de-theologie-morale-2006-3-page47.htm>. Acesso em: 05 jun. 2017.

ALICI, Luigi. Interrogatio mea, intentio mea: le mouvement de la pensée augustinienne. In: BOCHET, Isabelle (ed.). Augustin philosophe et prédicateur: Hommage à Goulven Madec, p. 371-388. Actes du colloque international organisé à Paris, les 8 et 9 septembre 2011. Collection des Études Augustiniennes, Série Antiquité, 195. Paris: Institut d'Études Augustiniennes, 2012. Disponível em: <https://u-pad.unimc.it/retrieve/handle/11393/142219/3226o/Lalici-1.pdf>. Acesso em: 01 jun. 2017.

AUGUSTINE, St. Confessiones. Translation by William Watts. In Two Volumes. Volume I. London/New York: William Heinemann/ The Macmillan CO., 1912.

AUGUSTín, San. Obras de San Agustín en edicion bilíngue - Obras Filosoficas: Contra los académicos, Del libre albedrío. De La cuantidad del alma. Del maestro. Del alma y su origen De la naturaleza del bien: contra los maniqueos. Traducción: Victorino Capánaga, Evaristo Seijas, Eusebio Cuevas et al. $3^{\text {a }}$ ed. Madrid: Biblioteca de Autores Cristianos, 1963. 
AUGUSTÍN, San. Obras completas de San Agustín - Introducción general y primeros escritos: Vida de San Agustín, escrita por San Posidio. Introducción a los Diálogos. Soliloquios. De la vida feliz. Del orden. $4^{\text {a }}$ ed. Madrid: Biblioteca de Autores Cristianos, 1969.

AUGUSTÍN, San. Obras completas de San Agustín, Tomo XL, Escritos vários $\left(2 .^{\circ}\right)$ : Ochenta y tres cuestiones diversas.-La adivinación diabólica.-Respuesta a ocho preguntas de Dulcido.- La piedad con los difuntos.-La utilidad Del ayuno.-La devastación de Roma.-Regla a los siervos de Dios.-Las Retractaciones.-Catálogo de los libros, tratados y cartas de San Agustín editado por San Posidio. Traducción de Pío de Luis, Moises $\mathrm{M}^{\mathrm{a}}$ Campelo, Teodoro c. Madrid. Madrid: Biblioteca de Autores Cristianos, 1995.

BERMON, Emmanuel. Le cogito dans la pensée de saint Augustin. Paris: Vrin, 2001, $432 \mathrm{p}$.

BRENTANO, Franz. El porvenir de la filosofía. Traducción del Alemán por Xavier Zubiri. Madrid: Revista de Occidente, 1936.

CÍCERO, Marco T. Acadêmicas. Trad.: José R. Seabra Filho. Belo Horizonte: Nova Acrópole, 2012.

DE ANDRADE, Marcelo P. O auto-conhecimento da mens no livro X do De Trinitate de Santo Agostinho. São Paulo, 2007, 115 f. Dissertação (Mestrado em Filosofia) - Pontifícia Universidade Católica de São Paulo.

DESCARTES, René. Meditações sobre Filosofia Primeira: Edição Bilíngue. Trad.: Fausto Castilho. Campinas: CEMODECON, 1999.162 p.

DUTTON, Blake D. Augustine and Academic Skepticism; A philosophical study. New York:Cornell University Express, 2016. 256 p.

GILSON, Étiene. Introdução ao estudo de Santo Agostinho. Tradução de Cristiane Negreiros Abbud Ayoub. São Paulo: Discurso Editorial: Paulus, 2006.

HEIDEGGER, Martin. Estudios sobre mística medieval. México: Fondo de Cultura Económica, 1997, 202 p.

HUSSERL, Edmund. Cartesianische Meditationen und Pariser Vorträge. Hsg. von S. Strasser. 2. Auflage. Hua I. Den Haag: Martinus Nijhoff, 1973.

MARCONDES, Danilo. Iniciação à história da filosofia: dos pré-socráticos a Wittgenstein. 6 ed., Rio de Janeiro: Jorge Zahar, 2001.

MARIN, Pascal. La quête du vrai dans le deuil de la métaphysique: la philosophie contemporaine à l'école de saint Augustin. Lumière \& Vie, Lyon, $\mathrm{n}^{\circ} 280$, octobredécembre 2008, p. 63-70. Disponível em: <http://lumiere-etvie.fr/resources/cariboost_files/LV_280_num_C3_A9ro_complet.pdf >. Acesso em: 31 mai. 2017. 
MATTHEWS, Gareth B. Santo Agostinho: a vida e as ideias de um filósofo adiante de seu tempo. Tradução Álvaro Cabral: Rio de Janeiro: Zahar, 2007.

PLATO. Complete Works. Edited, with introduction and notes, by John M. Cooper. Hutchinson. Indianapolis: Hackett, 1997.

SAVIAN FILHO, Juvenal. Seria o Sujeito uma Criação medieval? Temas de arqueologia filosófica, 190. Trans/Form/Ação, Marília, v. 38, n. 2, p. 175-204, Maio./Ago., 2015.

STOCK, Brian. Augustine's Inner Dialogue: The Philosophical Soliloquy in Late Antiquity. Cambridge: Cambridge University Press, 2010, p. 96.

TONIOLO, João C. Agostinho e a reinterpretação do "nosce te ipsum" no De Trinitate X. Campinas, 2015, 125 f. Dissertação (Mestrado em Filosofia) Universidade Estadual de Campinas.

Recebido em: 10.01.2018 Aprovado em: 10.10.2018 